UNIVERSITAS MUHAMMADIYAH MALANG JP2SD (JURNAL PEMIKIRAN

DAN PENGEMBANGAN SEKOLAH DASAR)

http://ejournal.umm.ac.id/index.php/jp2sd

p-ISSN: 2338-1140 e-ISSN: 2527-3043

\title{
Pengaruh Penerapan Model Pembelajaran Snowball Throwing Terhadap Hasil Belajar Tematik Sekolah Dasar
}

\author{
Novia Tri Ananda a1, Kuncahyono a2*, Sudjalil b3 \\ aPendidikan Guru Sekolah Dasar, Universitas Muhammadiyah Malang, Indonesia \\ bendidikan Bahasa Indonesia, Universitas Muhammadiyah Malang, Indonesia \\ ${ }^{1}$ noviatrinanda@gmail.com, ${ }^{2}$ kuncahyono@umm.ac.id, ${ }^{3}$ sudjalil_63@yahoo.com \\ *Penulis korespondensi
}

\begin{tabular}{ll}
\hline INFORMASI ARTIKEL \\
\hline Riwayat: & \\
Diterima & 8 Agustus \\
& 2020 \\
Revisi & 21 Agustus \\
& 2020 \\
Dipublikasikan & 22 September \\
& 2020
\end{tabular}

Kata kunci:

Pengaruh, Snowball

Throwing, Hasil belajar

tematik

\begin{abstract}
ABSTRAK
Penelitian ini bertujuan untuk mengetahui pengaruh penerapan model pembelajaran Snowball Throwing terhadap hasil belajar tema 8. Desain penelitian ini Quasy Experimental Design dengan bentuk penelitian Nonequivalent Control Grup Design, sampel penelitian kelas VA dan VB dengan teknik purposive sampling. Data penelitian ini diperoleh dari rata-rata nilai pretes dan posttes kemudian dianalisis menggunkan statistik parametrik dengan bantuan software SPSS 21.0 For Windows. Uji hipotesis menggunakan independen sampel t tes diperoleh $\mathrm{t}$ hitung 3,940 > t tabel 1,464 dan nilai sig (2-tailed) 0,000 < 0,05 artinya ditolak/ diterima maka dapat disimpulkan ada pengaruh yang signifikan penerapan model pembelajaran Snowball Throwing terhadap hasil belajar tema 8 pada siswa kelas V di MI Butanul Ulum Kota Batu.
\end{abstract}

Keywords:
Influence, Snowball
Throwing, thematic Outcomes
Learning

Copyright (C) 2020, Novia Tri Ananda, Kuncahyono, Sudjalil This is an open access article under the CC-BY-SA license

\section{ABSTRACT}

This study aims to determine the effect of the application of thelearning model Snowball Throwing on the learning outcomes of theme 8. The design of this study is Quasy Experimental Design with the form of Nonequivalent Control Design Group, the research sample is VA and VB with purposive sampling technique. The data of this study were obtained from the average value of the pretest and posttest then analyzed using parametric statistics with the help ofsoftware SPSS 21.0 For Windows. Hypothesis testing using independent samples $\mathrm{t}$ test obtained $\mathrm{t}$ count $3.940>\mathrm{t}$ table 1.464 and sig value (2-tailed) $0,000<0.05$ means rejected / accepted then it can be concluded that there is a significant effect of the application of thelearning model Snowball Throwing to the learning outcomes of theme 8 on grade V students at MI Butanul Ulum Kota Batu. 
How to cite: Novia Tri Ananda, Kuncahyono, Sudjalil. (2020). Pengaruh Penerapan Model Pembelajaran Snowball Throwing Terhadap Hasil Belajar Tematik Sekolah Dasar. Jurnal Pemikiran dan Pengembangan Sekolah Dasar, Vol 8 No 2, 157-162. doi: https://doi.org/10.22219/jp2sd. v8i2.14901

\section{PENDAHULUAN}

Mengajar dalam konteks pendidikan Sekolah Dasar di era modern tidak hanya sekedar menyampaikan materi pembelajaran saja tetapi juga mengolah lingkungan belajar supaya siswa dapat belajar maka penyelenggaraan pembelajaran merupakan tugas utama bagi guru. Objek yang dipelajari siswa hanya bertindak sebagai media sedangkan pengetahuan diciptakan dan dibentuk oleh pikiran individu itu sendiri (Fathurrohman, 2015:20). Menurut pendapat yang dikemukakan oleh (Suprihatiningrum, 2013:15) belajar merupakan proses dan usaha yang dilakukan oleh siswa untuk memperoleh sesuatu perubahan tingkah laku yang dapat dilihat secara langsung atau tidak langsung sebagai hasil pengalaman sendiri dalam berinteraksi dengan lingkungannya.

Belajar merupakan proses seseorang mendapatkan pengetahuan atau informasi baru serta perubahan tingkah laku dari pengalaman interaksi dengan lingkungannya kapanpun dan dimanapun berada, sedangkan hasil belajar merupakan suatu penilaian akhir yang diperoleh dari proses dan pengenalan yang berulang-ulang yang tersimpan dalam jangka yang waktu lama oleh karena itu, makna belajar bukan hanya untuk mendorong siswa untuk menghafal materi melainkan ketika seorang siswa berperilaku, bereaksi, dan merespons sebagai hasil dari pengalaman dari perilaku sebelumnya. Model pembelajaran merupakan suatu perencanaan sebagai pedoman yang dapat digunakan dalam pelaksanaan pembelajaran serta untuk menentukan perangkat-perangkat pembelajaran yang cocok, adapun pembelajaran kooperatif dikembangkan dalam berbagai teknik seperti Think Pair Share, Jigsaw, STAD, Snowball Throwing, TGT dan sebagainya. Penerapan model dan media pembelajaran memiliki pengaruh yang signifikan terhadap hasil belajar siswa (Prabawati et al., 2017).

Model Snowball Throwing pada pelaksanaannya banyak melibatkan siswa, disini guru hanya sebagai penentu topik awal untuk dibahas siswa kemudian siswa dibagi menjadi beberapa kelompok heterogen membahas topik dipilihkan oleh guru, ketua bersama kelompoknya memastikan setiap siswa diwajibkan membuat satu pertanyaan pada sebuah kertas yang dilempar (Throwing) seperti bola salju (Snowball) kepada siswa lainnya yang harus dijawab oleh penerima.Sejalan dengan pendapat yangdikemukakan oleh (Shoimin,2014:174) bahwa model pembelajaran Snowball Throwing merupakan pengembangan model pembelajaran diskusi yang merupakan salah satu dari bagian model pembelajaran kooperatif tetapi, pada kegiatan pembelajarannya dapat dikondisikan sedemikian rupa agar menyenangkan dan bermakna bagi siswa. Berdasarkan hasil observasi awal pada bulan November sampai desember 2019 di MI Bustanul Ulum Kota Batu yaitu dilakukan pretes pada kelas VA, VB dan VC didapatkan hasil bahwa sebagian besar hasil belajar siswa belum mencapai KKM.

Snowball Throwing dalam proses belajar mengajar telah digunakan sebagai model yang digunakan untuk mencapai tujuan pembelajaran yang telah ditentukan, tingkat keberhasilan proses belajar mengajar menggunakan model ini dapat dilihat dengan meningkatnya hasil belajar kongnitif siswa. Disimpulkan bahwa dalam belajar tematik harus benar-benar menjadi pembelajaran yang bermakna bagi siswa yang memerlukan keterampilan guru dalam memberikan inovasi, kreatifitas, dan keaktifan guru dalam pembelajaran yang dikemas secara menyenangkan bagi siswa.

Novia Tri Ananda, Kuncahyono, Sudjalil. Pengaruh Penerapan Model Pembelajaran Snowball Throwing Terhadap Hasil Belajar Tematik Sekolah Dasar 
Berdasarkan permasalahan di atas, penelitian ini penting dilakukan pada kelas $\mathrm{V}$ di MI Bustanul Ulum Kota Batu, dan peneliti menggunakan salah satu model pembelajaran Snowball Throwing, model Snowball Throwing dipilih karena melalui model pembelajaran Snowball Throwing ini memiliki karakteristik dapat membantu dalam pembelajaran serta meningkatkan hasil belajar siswa pada materi pembelajaran dengan melatih siswa tanggap menerima pesan dan menyampaikan pesan dalam bentuk soal, sehingga meningkatkan kemampuan siswa pada aspek kongnitif yang dirancang dengan pembelajaran lebih nyaman untuk belajar dan mencapai hasil belajar yang tinggi. Dengan demikian tujuan penelitian ini yaitu untuk mengetahui pengaruh model pembelajaran snow ball throwing terhadap hasil belajar siswa sekolah dasar.

\section{METODE}

Penelitian ini dilaksanakan di MI Bustanul Ulum Kota Batu yang beralamat di Jl. Cempaka No. 25 Desa Pesanggrahan, Kecamatan Batu, Kota Batu Jawa Timur. MI Bustanul Ulum kota Batu berada di pinggir kota batu berlokasi di belakang masjid Nurl Hidayah dan dekat dengan SMP Darush Sholihin Batu, sedangkan penelitian dilaksanakan pada semester 2 tahun ajaran 2018/2019.

Penelitian ini merupakan penelitian eksperimen menggunakan jenis penelitian Quasy Experimental Design. (Sugiyono, 2017:77) menyatakan bahwa bentuk desain ini mempunyai kelompok kontrol akan tetapi tidak dapat berfungsi sepenuhnya untuk mengontrol variabel-variabel luar yang mempengaruhi pelaksanaan penelitian eksperimen dengan menggunkan bentuk penelitian Nonequivalent Control Grup Design yang dibedakan dengan adanya pretest dan posttes menggunakan dua kelompok yaitu kelas eksperimen siswa diberikan perlakuan menggunakan model pembelajaran Snowball Throwing dan kelas kontrol diberikan perlakuan menggunakan metode pembelajaran konvensional, berikut ini bentuk penelitian Nonequivalent Control Group Design.

\begin{tabular}{cccc}
\multicolumn{4}{c}{ Table 1. Penelitian Nonequivalent Control Group Design } \\
\hline Kelompok & Pre-Test & Perlakuan & Post-Test \\
\hline Kelas Kontrol & $\mathrm{O} 1$ & $\mathrm{X}$ & $\mathrm{O} 2$ \\
\hline $\begin{array}{c}\text { Kelas } \\
\text { Eksperimen }\end{array}$ & $\mathrm{O} 3$ & $\mathrm{X}$ & $\mathrm{O} 4$ \\
\hline
\end{tabular}

Populasi dalam penelitian ini seluruh siswa kelas V MI Bustanul Ulum Kota Batu dengan jumlah keseluruhan populasi kelas V yaitu 107 siswa yaitu kelas VA dengan jumlah siswa 36 dan VB dengan jumlah 36 siswa dan kelas VC dengan jumlah siswa 35. Instrumen penelitian yang digunakan yaitu instrumen tes soal pretes dan posttes berupa soal pilihan ganda, instrumen observasi untuk mengamati keadaan kelas yang diteliti serta kegiatan pembelajaran dan cara mengajar oleh observer dan instrumen dokumentasi berupa foto-foto saat penelitian berlangsung yang diperlukan sebagai bukti telah dilaksanakannya penelitian.

\section{HASIL DAN PEMBAHASAN}

Studi pendahuluan diadakan untuk memperoleh data awal tentang keadaan tempat yang akan dipergunakan untuk penelitian.MI Bustanul Ulum Kota Batu dipilih untuk dijadikan tempat penelitian dan studi pendahuluan dilaksanakan pada 21-22 Februari 2019. Dari kegiatan ini diperoleh informasi tentang keadaan pembelajaran 
yang ingin diteliti, serta diperoleh arahan untuk melaksanakan penelitian di kelas V berkaitan dengan penyajian materi pada tema 8 .

Pada penelitian ini dipersiapkan perangkat pembelajaran yang memuat perangkat pembelajaran untuk kelas kontrol dan kelas eksperimen. Perangkat pembelajaran terdiri dari materi ajar, RPP, lembar kerja siswa, kisi-kisi lembar evaluasi, lembar evaluasi (instrumen pre-test dan post-test), dan lembar penilaian. Dalam hal ini dilakukan kerja sama dengan guru kelas yang bersangkutan yaitu guru kelas V-A dan kelas V-B. Penyusunan instrumen penelitian juga dikonsultasikan dengan ahli validasi soal untuk mendapatkan beberapa perbaikan berkaitan dengan isi dan kualitas perangkat pembelajaran.

Berikut ini uraian hasil penghitungan statistik menggunakan bantuan software SPSS 21.0 For Windows untuk menjawab "Pengaruh penerapan model Snowball Throwing terhadap hasil belajar tema 8 pada kelas V di MI Bustanul Ulum Kota Batu", peneliti terlebih dahulu harus melakukan berbagai penghitungan diantaranya 1) Uji validitas 2) uji Reliabilitas, untuk uji prasyarat meliputi uji normalitas, uji homogenitas dan 5) uji hipotesis adapun hasil penghitungannya yaitu.

\section{Uji Validitas}

Hasil uji validitas untuk instrument soal dapat dilihat pada statistik, yaitu nilai $\mathrm{df}=\mathrm{N}-2$, disini saya menggunakan $\mathrm{N}-2$ (jumlah siswa) maka $\mathrm{df}=38-2=36$, jadi kita melihat nilai d $36=0.270$, jika nilai lebih kecil dari 0.270 atau maka item tersebut dinyatakan tidak valid dengan taraf signifikan 0,05 . Dari hasil uji validitas butir soal menggunakan program SPSS 21.0 for windows diperoleh hasil soal yang valid sejumlah 18 soal yaitu pada nomor $1,2,5,7,8,9,13,15,17,18,20,23,24,25,26$, 27, 30 sehingga peneliti menggunakan 18 butir soal pilihan ganda untuk tes hasil belajar siswa berupa pretes dan posttes.

\section{Uji Reliabilitas}

Dari hasil uji reliabilitas butir soal menggunakan program SPSS 21.0 for windows diperoleh hasil dari 18 dari 30 soal reliabel dengan bentuk soal pilihan ganda yang dilakukan pada 38 siswa di SDN Girimoyo 2 Kabupaten Malang dinyatakan reliable dengan perolehan Cronbach's Alpha hitung sebesar 0,702 pada nomor 1, 2, 5, $7,8,9,13,15,17,18,20,23,24,25,26,27,30$.

\section{Uji Normalitas}

Uji normalitas digunakan untuk menunjukkan bahwa data penelitian yang berdistribusi normal atau tidak menggunakan kolmogorof Smirnov diperoleh sig 0,252 $>0,05$ dan postes sig 0,467 >0,05. Pada kelas kontrol prettes diperoleh sig 0,252 > $0,05$, posttes $0,366>0,05$ juga berdisribusi normal dengan taraf signifikasi ( $\operatorname{sig})>0,05$ maka data berdistribusi normal sehingga kriteria terpenuhi.

\section{Uji Homogenitas}

Uji homogenitas bertujuan untuk menunjukkan bahwa dua kelompok data sampel berasal dari populasi yang mempunyai variasi yang sama atau tidak memiliki perbedaan yang mencolok menggunakan uji levene diperoleh data hasil belajar siswa homogen dengan nilai signifikansi (sig) sebesar 0,230>0,05 dengan demikian dapat disimpulkan bahwa varian data posttes kelas eksperimen dan data posttes kelas kontol sama atau homogen sehingga kriteria terpenuhi. 


\section{Uji Hipotesis}

Uji hipotesis dilakukan setelah uji prasyarat terpenuhi yaitu data harus berdistribusi normal dan homogen kemudian uji hipotesis menggunakan Independen sampel t test yaitu untuk mengetahui apakah terdapat perbedaan rata-rata dari dua sampel yang tidak berpasangan atau berbeda kelompok diperoleh hasil belajar antara kelas eksperimen dan kelas kontrol diperoleh bahwa thitung 3,940>t tabel 1,464 dengan taraf signifikansi sig (2-tailed) yaitu 0,000 < 0,05 maka dapat diambil kesimpulan ditolak/ diterima artinya terdapat pengaruh yang signifikan untuk penerapan model pembelajaran Snowball Throwing terhadap hasil belajar tema 8 pada siswa kelas V di MI Butanul Ulum Kota Batu. Dari data yang sudah dipaparkan dapat diambil kesimpulan bahwa dengan menggunakan model pembelajara Snowball Throwing berpengaruh signifikan terhadap peningkatan hasil belajar siswa tema 8 , hal tersebut diperkuat dengan pendapat (Shomin, 2014:176) yang menyatakan bahwa dengan menerapkan model Snowball Throwing mampu meningkatkan ketercapaian aspek kongnitif.

Sejalan dengan pendapat (Kusumawati, 2017:9) manyatakan bahwa model pembelajaran Snowball Throwing jauh lebih efektif dibandingkan dengan menggunakan metode pembelajaran konvensional yang biasa diterapkan oleh sekolah dengan hasil posttes yang diperoleh kelas eksperimen memiliki nilai terendah 75 dan nilai tertinggi 90 dengan nilai rata-rata 83,23. Dapat disimpulkan berdasarkan teori dari para ahli dan kajian penelitian yang relevan terdahulu, penelitian ini dikatakan sudah relevan dan berpengaruh signifikaan dibuktikan melalui hasil belajar siswanya lebih baik pada kelas eksperimen dibandingkan dengan kelas kontrol yang hanya menerapkan metode konvensional seperti yang biasa diterapkan oleh sekolah

\section{SIMPULAN}

Terdapat pengaruh yang signifikan penerapan model pembelajaran Snowball Throwing dibuktikan pada penelitian ini kelas eksperimen memiliki rata-rata 70,56 dibandingkan kelas kontrol 62,08 sehingga terlihat jelas terdapat pebedaan hasil belajar antara kelas eksperimen lebih tinggi dibandingkan kelas kontrol. Adapun hasil pengujian statistik dengan menggunakan independen sampel t-test diperoleh hasil taraf signifikansi sig (2-tailed) yaitu $0,000<0,05$ atau dapat diartikan bahwa ditolak dan diterima yang berarti ada perbedaan yang signifikan antara hasil belajar siswa kelas eksperimen dan kelas kontrol. Penerapan model pembelajaran Snowball Throwing memiliki peningkatan hasil belajar yang lebih tinggi dibandingkan dengan pembelajaran menggunkan metode konvensional, untuk itu peneliti menyarankan agar guru kelas V Sekolah Dasar khususnya pada tema 8 "lingkungan sahabat kita" subtema "manusia dan lingkungan" pembelajaran ke 4 menerapkan model pembelajaran Snowball Throwing dapat memberikan pengalaman baru bagi siswa untuk menggali kemampuannya. Untuk mendapatkan hasil yang lebih baik sebaiknya sebelum melakukan penelitian ini pada kelas eksperimen yang menerapkan model pembelajaran Snowball Throwing dilakukan pembiasaan terlebih dahulu beberapa pertemuan agar siswa terbiasa dan tidak mengalami kendala saat mengikuti proses pembelajaran. 


\section{REFERENSI}

Annisa'ul Mu'affifah, Budiyono. 2015. Pengaruh Model Pembelajaran Kooperatif Tipe Snowball Throwing Terhadap Hasil Belajar Satuan Ukur Siswa Kelas IV Di Sekolah Dasar. JPGSD. 3 (2): 781-783. (Online), dalam (http://jurnalmahasiswa.unesa.ac.id/index.php/jurnal-penelitianpgsd/article/view/15483)

Fathurrohman, Muhammad. 2015. Model-model Pembelajaran Inovatif: Alternatif Desain

Pembelajaran yang Menyenangkan. Jogjakarta:Ar-Ruzz Media.

Huda, Miftahul. 2013. Model-model Pengajaran dan Pembelajaran Isu-isu Metodis dan Paradigmatis. Yogyakarta:Pustaka Pelajar.

Imron, Ali. 2011. Manajemen Peserta Didik Berbasis Sekolah. Jakarta: PT Bumi Aksara. Kusumawati, Naniek. 2017. Pengaruh Model pembelajaran Kooperatif Dengan Snowball Throwing Terhadap Hasil Belajar IPA Pada Siswa Kelas IV SDN Bondrang Kecamatan Sawoo Kabupaten Ponorogo. JPGSD. 2 (1). (Online),(http://ibriez.iainpono rogo.ac.id/index.php/ibriez/art icle/view/19/12)

Majid, Abdul. 2014. Pembelajaran Tematik Terpadu. Bandung: PT Remaja Rosdakarya.

Najib, Sulaiha. 2006. Pembangunan karakter pada anak, mamajemen pembelajaran Guru menuju sekolah efektif. Surabaya: Surabaya Bandung: PT Remaja Intelektual Club. Rosdakarya.

Masyhuri, M. Zainuddin. 2008. Metodologi Penelitian Pendekatan Praktis dan Aplikatif. Bandung: PT Refika Aditama

Prabawati, R. N., Yayuk, E., \& Kuncahyono, K. (2017). Pengaruh Media LKS Berbasis Model Take And Give Terhadap Hasil Belajar Ipa Siswa Kelas V SD Negeri Jabung 01 Kec. Jabung Kab. MALANG. Jurnal Pemikiran Dan Pengembangan Sekolah Dasar (JP2SD), 5(2), 750-757.

Trianto. 2007. Model Pembelajaran Terpadu. Jakarta: Prestas Pustaka Publisher. Rusman. 2011. Model-model Pembelajaran. Jakarta: PT Raja Grafindo Persada.

Shoimin, Aris. 2014. 68 Model Pembelajaran Inovatif dalam Kurikulum 2013. Yogyakarta: Ar.Ruzz Media.

Sugiyono. 2017. Metode Penelitian Kuantitatif, Kualitatif dan R\&D. Bandung: Alfabeta Suprihatiningrum, Jamil. 2013. Strategi Pembelajaran Teori dan Aplikasi. Jogjakarta: AR-Ruzz Media.

Surapranata, Sumarna. 2004. Analisis, Validitas, Reliabilitas dan Interpretasi Hasil Tes: Implementasi Kurikulum. 